Short Report

\title{
Ambiguous Group Membership Is Extracted Automatically From
} Faces

\author{
Nicholas O. Rule, ${ }^{1}$ C. Neil Macrae, ${ }^{2}$ and Nalini Ambady ${ }^{1}$ \\ ${ }^{1}$ Tufts University and ${ }^{2}$ University of Aberdeen
}

To economize the demands of person perception, individuals quickly and accurately categorize others into groups (Macrae \& Bodenhausen, 2000). Indeed, for groups with salient perceptual markers (e.g., sex, age, race), category activation is deemed to be an unavoidable consequence of the person-perception process (Bargh, 1999; Brewer, 1988; Fiske \& Neuberg, 1990). But what about social groups with less obvious physical cues, do they also trigger automatic person categorization? Recent data hint that this may, indeed, be the case. Take, for example, male sexual orientation. Although the cues to male sexual orientation are ostensibly ambiguous (yielding categorization accuracy of approximately $60-70 \%$ against a chance guessing rate of $50 \%$ ), differences between gay and straight men can be judged significantly better than chance following very brief exposure to a target (i.e., $50 \mathrm{~ms}$; Rule \& Ambady, 2008) and can modulate incidental memory for previously encountered faces (Rule, Ambady, Adams, \& Macrae, 2007). What these findings suggest is that, like sex, age, and race, information pertaining to male sexual orientation may be extracted automatically from faces (see Rule, Ambady, Adams, \& Macrae, 2008). To explore this possibility, we employed a lexical decision task in which participants responded to gay and straight verbal associates after the presentation of facial primes. If exposure to a face is sufficient to trigger category activation (i.e., information pertaining to sexual orientation), performance should be facilitated on prime-congruent trials.

\section{METHOD}

\section{Participants and Design}

Forty undergraduates (18 females, 22 males; mean age $=18.93$ years, $S D=1.07$ years) participated for either partial credit in an introductory psychology course or cash compensation. The

Address correspondence to Nicholas O. Rule, Tufts University, Department of Psychology, 490 Boston Ave., Medford, MA 02155, e-mail: nicholas.rule@tufts.edu. experiment had a 2 (target: straight or gay) $\times 2$ (word type: straight associate or gay associate) repeated measures design.

Stimulus Materials and Procedure A subset of 20 head shots of gay $(n=10)$ and straight $(n=10)$ men were randomly selected from a previously validated, standardized set of photographs obtained from Internet dating sites (for more details, see Rule \& Ambady, 2008; Rule et al., 2008). The targets self-identified as either gay or straight and did not differ systematically along dimensions such as facial attractiveness. Pretesting showed that the faces were categorized with accuracy better than chance $(n=27 ; M=76 \%, S D=14 \%)$, $t(19)=9.87, p<.001, r=.89$. Ten words relating to gay stereotypes (e.g., fabulous, rainbow) and 10 words relating to straight stereotypes (e.g., rough, football) were selected based on pretests. For the purpose of the lexical decision task, 20 nonword letter strings were constructed from these stereotyperelated items.

Participants were instructed that they would see a series of letter strings interspersed by faces and that their task was to indicate whether the letter string was a word or nonword as quickly and accurately as possible by pressing the "F" and "J" keys. Keyresponse mappings were counterbalanced across participants. For each trial, participants were presented with a fixation cross for $500 \mathrm{~ms}$, after which a face prime was presented for $100 \mathrm{~ms}$. The face was then immediately replaced by one of the letter strings or words, which remained on the screen until the participant made a response. The task consisted of 80 randomly ordered trials, such that each face was presented on four occasions: with a straight associate, with a gay associate, and with two nonwords.

\section{RESULTS}

Mean categorization latencies served as the dependent measure of interest. Given the presence of outlying responses in the data set, response times that were slower than 2.5 standard deviations 


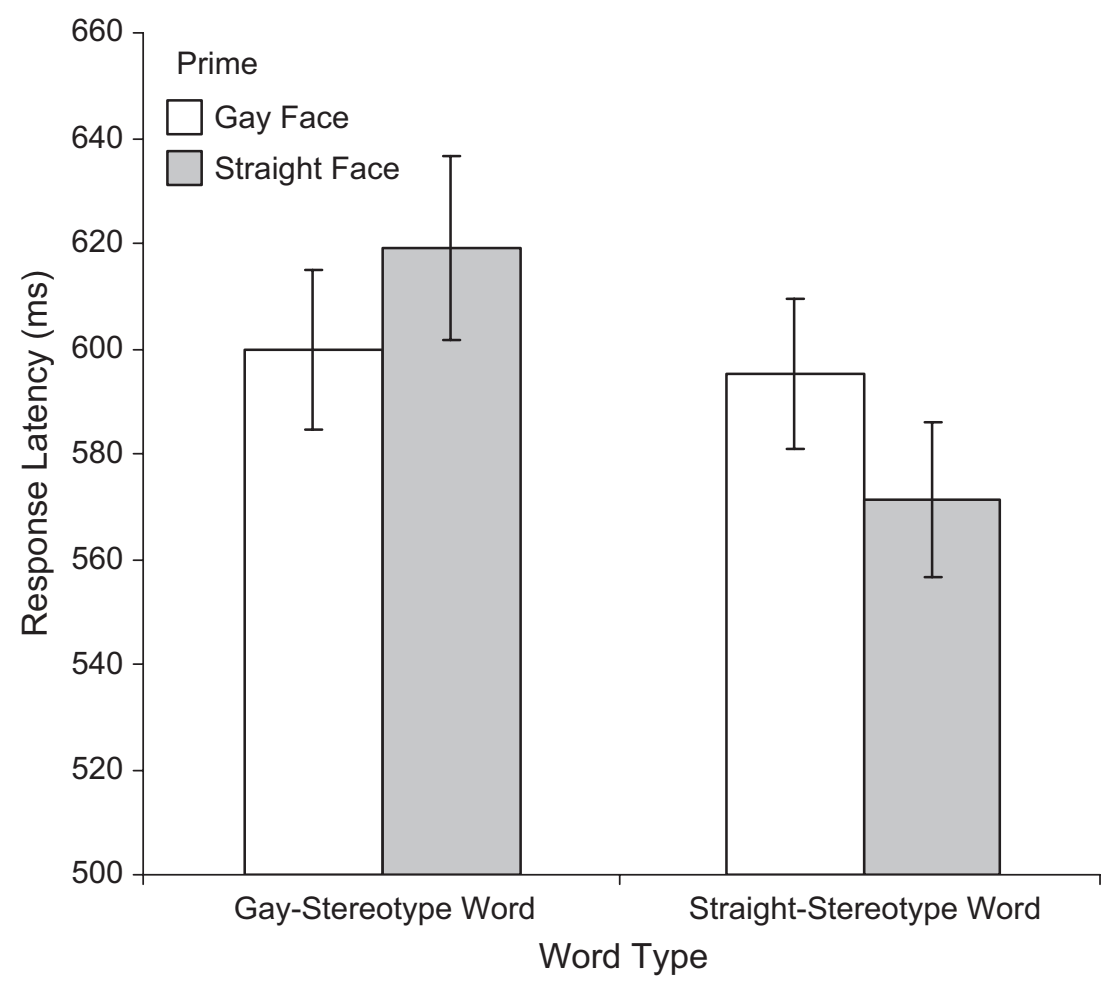

Fig. 1. Mean response latency for classifying stereotype-related words as a function of facial prime. Error bars indicate standard errors.

from the mean were excluded from the analysis, as were trials on which errors were committed. This resulted in $4 \%$ of the data being excluded from statistical analysis. A 2 (target: straight or gay) $\times 2$ (word type: straight associate or gay associate) repeated measures analysis of variance was performed on the data. This analysis yielded a main effect of word type on task performance, $F(1,39)=19.50, p<.001, r=.58$. However, the analysis also returned a significant Target $\times$ Word Type interaction, $F(1,39)=20.51, p<.001, r=.59$ (see Fig. 1). Simpleeffects analyses showed that responses to gay associates were faster when the words were primed with gay faces than when words were primed with straight faces, $t(39)=2.13, p=.039$, $r=.32$, an effect that was reversed for straight associates, $t(39)$ $=2.81, p=.007, r=.41$. Moreover, both male and female participants showed the significant interaction when analyzed separately, $F_{\mathrm{s}} \geq 5.02, p \mathrm{~s} \leq .036, r \mathrm{~s} \geq .44$. An additional analysis, in which words were treated as random effects, also yielded an interaction of associate and prime, $F(1,38)=9.08$, $p=.005, r=.44$. Finally, responses to nonwords were unaffected by the priming faces, $t(39)<0.01, p=.998, r<.01$.

\section{DISCUSSION}

Exposure to faces of members of a perceptually ambiguous group facilitated access to associated stereotypic material. This finding is noteworthy for a number of reasons. Although sexual orientation has not been considered to be a property akin to the sex, age, or race of a person (Macrae \& Bodenhausen, 2000), our findings demonstrate that, like these primary categories, this information is also automatically extracted from faces. What this suggests is that theoretical models of person perception may have significantly underestimated the extent of category activation during social interaction (Brewer, 1988; Fiske \& Neuberg, 1990). Specifically, the automaticity of person categorization associated with perceptually salient groups would appear to extend to categories with less obvious visual markers (Rule et al., 2008). Thus, the perceptual processes underlying person categorization support a broader range of categorical products (e.g., cultural stereotypes) than has hitherto been assumed (Fiske \& Neuberg, 1990). This observation further underscores the pivotal and pervasive status of categoryrelated processing during person perception.

Acknowledgments - This research was supported in part by a National Science Foundation Graduate Research Fellowship (to N.O.R.), a Royal Society-Wolfson Fellowship (to C.N.M.), and National Science Foundation Grant BCS-0435547 (to N.A.).

\section{REFERENCES}

Bargh, J.A. (1999). The cognitive monster: The case against the controllability of automatic stereotype effects. In S. Chaiken \& Y. 
Trope (Eds.), Dual process theories in social psychology (pp. 361382). New York: Guilford.

Brewer, M.B. (1988). A dual process model of impression formation. In R.S. Wyer, Jr., \& T.K. Srull (Eds.), Advances in social cognition (Vol. 1, pp. 1-36). Hillsdale, NJ: Erlbaum.

Fiske, S.T., \& Neuberg, S.L. (1990). A continuum model of impression formation from category-based to individuating processes: Influences of information and motivation on attention and interpretation. In M.P. Zanna (Ed.), Advances in experimental social psychology (Vol. 3, pp. 1-74). San Diego, CA: Academic Press.

Macrae, C.N., \& Bodenhausen, G.V. (2000). Social cognition: Thinking categorically about others. Annual Review of Psychology, 51, 93-120.
Rule, N.O., \& Ambady, N. (2008). Brief exposures: Male sexual orientation is accurately perceived at $50 \mathrm{~ms}$. Journal of Experimental Social Psychology, 44, 1100-1105.

Rule, N.O., Ambady, N., Adams, R.B., Jr., \& Macrae, C.N. (2007). Us and them: Memory advantages in perceptually ambiguous groups. Psychonomic Bulletin \& Review, 14, 687-692.

Rule, N.O., Ambady, N., Adams, R.B., Jr., \& Macrae, C.N. (2008). Accuracy and awareness in the perception and categorization of male sexual orientation. Journal of Personality and Social Psychology, 95, 1019-1028.

(RECEIVED 7/5/08; REVISION ACCEPTED 10/29/08) 